\title{
G0S2 is an all-trans-retinoic acid target gene
}

\author{
SUTISAK KITAREEWAN ${ }^{1}$, STEVEN BLUMEN ${ }^{1}$, DAVID SEKULA ${ }^{1}$, REID P. BISSONNETTE ${ }^{5}$, \\ WILLIAM W. LAMPH ${ }^{5}$, QINGPING CUI ${ }^{4}$, ROBERT GALLAGHER ${ }^{4}$ and ETHAN DMITROVSKY ${ }^{1-3}$ \\ Departments of ${ }^{1}$ Pharmacology and Toxicology and ${ }^{2}$ Medicine, and ${ }^{3}$ Norris Cotton Cancer Center, \\ Dartmouth Medical School, Hanover, NH 03755 and Dartmouth-Hitchcock Medical Center, \\ Lebanon, NH 03756; ${ }^{4}$ Department of Medicine and Albert Einstein Cancer Center, \\ Montefiore Medical Center, Bronx, NY 10467; ${ }^{5}$ Ligand Pharmaceutical, San Diego, CA 92121, USA
}

Received March 14, 2008; Accepted May 9, 2008

DOI: 10.3892/ijo_00000021

\begin{abstract}
All-trans-retinoic acid (RA) treatment of acute promyelocytic leukemia (APL) cases expressing the $t(15 ; 17)$ product, PML/RAR $\alpha$, is a successful example of differentiation therapy. Uncovering RA target genes is of considerable interest in APL. This study comprehensively examines in APL cells transcriptional and post-transcriptional regulation of the novel candidate RA target gene, G0S2, the $\mathrm{G}_{0} / \mathrm{G}_{1}$ switch gene. Reverse transcription (RT)-polymerase chain reaction (PCR) and heteronuclear PCR assays performed +/treatment with the protein synthesis inhibitor cycloheximide (CHX) revealed G0S2 induction within $3 \mathrm{~h}$ of RA-treatment. Treatment with the RNA synthesis inhibitor actinomycin D did not implicate G0S2 transcript stabilization in the RA-mediated increase of G0S2 mRNA expression. Promoter elements of G0S2 were cloned into a reporter plasmid and retinoic acid receptor (RAR) co-transfection assays confirmed transcriptional activation after RA-treatment. Consistent with G0S2 being a direct RA target gene, retinoic acid response element (RARE) half-sites were found in this promoter. Mutation of these sites blocked RA-transcriptional activation of G0S2. To extend analyses to the protein expression level, a polyclonal anti-G0S2 antibody was derived and detected murine and human G0S2 species. G0S2 protein was rapidly induced in cultured NB4-S1 human APL cells and in APL transgenic mice treated with RA. An RAR pan-antagonist confirmed dependence on RARs for this induction. That these findings are clinically relevant was shown by analyses of APL cells derived directly from patients. These leukemic cells induced both a prominent increase in the cellular differentiation marker nitrotetrazolium blue (NBT) staining and marked increase in G0S2 expression. Taken together, these findings
\end{abstract}

Correspondence to: Dr Ethan Dmitrovsky, 7650 Remsen, Department of Pharmacology and Toxicology, Dartmouth Medical School, Hanover, NH 03755, USA

E-mail: ethan.dmitrovsky@dartmouth.edu

Key words: G0S2, retinoic acid, target gene, differentiation indicate G0S2 is an RA target gene. The functional role of G0S2 in retinoid response of APL warrants further study.

\section{Introduction}

All-trans-retinoic acid (RA) treatment of acute promyelocytic leukemia (APL) is a model of successful differentiationbased therapy of leukemia in patients $(1,2)$. RA is a derivative of vitamin A and is essential for diverse biological effects, including reproduction, vision and immune function (3). RA acts as a signaling molecule that broadly modulates gene transcriptional activities, which confers both down-regulation and up-regulation of target genes (4-6). There are two families of nuclear retinoid receptors (retinoic acid receptors, RARs, and retinoid X receptors, RXRs). In the absence of the ligand RA, RARs and RXRs can heterodimerize and form a complex with inhibitory co-repressors. This complex is bound to retinoic acid response elements (RARE) of target genes, as reviewed $(2,7)$. Upon binding to RA, the co-repressor complex is released and a stimulatory co-activator complex is recruited that modifies chromatin structure and initiates transcription of target genes that regulate growth and differentiation. Expression of the PML/RAR $\alpha$ fusion protein that is a product of the $t(15 ; 17)$ rearrangement found in APL also heterodimerizes with RXRs and binds to RAREs and confers transcriptional repression through dominant-negative effects. However, physiological concentrations (nM levels) of RA are not sufficient to release the co-repressor from the transcriptional complex due to its strong association with the $\mathrm{PML} / \mathrm{RAR} \alpha$ fusion protein, as reviewed (2). This interrupts normal retinoid and RXR differentiation pathways and interferes with regulatory effects of PML that leads to accumulation of undifferentiated promyelocytes.

Mechanisms of RA actions that lead to APL remission are intensively studied (reviewed in refs. 2,8-10). Pharmacological dosages ( $\mu \mathrm{M}$ levels) of RA trigger critical signaling events including release of the co-repressor, and recruitment of the co-activator complexes, as well as degradation of PML/RAR $\alpha$ which results in overcoming dominant-negative effects of this fusion protein. Together, these lead to terminal differentiation of APL cells. Retinoid degradation of the fusion protein involves ubiquitin-proteasome, UBE1L, and caspasedependent pathways (11-13). 
Microarray analyses of cultured APL cells revealed RA activates gene expression including G0S2 in RA-sensitive, but not RA-resistant APL cells (14). One of the most prominently induced species is G0S2, a member of the $G_{0} / G_{1}$ switch gene family, which was first reported as markedly induced in mononuclear hematopoietic cells following treatment with the lectin concanavalin A and the inhibitor of protein synthesis, cycloheximide (CHX) $(15,16)$. Agonists of the peroxisomeproliferator-activated receptors (PPARs) were reported to induce G0S2 expression (17). Because its mRNA induced expression coincided with cell cycle progression from G0 to G1 by lectin- or CHX-treatment of lymphocytes $(15,16,18,19)$ and induction during differentiation of adipocytes by PPAR ligands (17), cell cycle regulation and differentiation roles were proposed for G0S2.

The mechanistic basis for RA-mediated differentiation of APL is under study, as reviewed (2). Yet, the identity of involved target genes remains to be discerned. Findings from our team and others (14-20), led us to hypothesize that G0S2 is a target gene for RA regulation. This study was undertaken to explore this hypothesis and provide evidence for G0S2 as a direct retinoid target gene in APL.

\section{Materials and methods}

Chemicals and antibodies. RA, CHX, actinomycin D and dimethyl sulfoxide (DMSO) were each purchased (Sigma, St. Louis, MO), as were G418, penicillin/streptomycin, Lglutamine (Mediatech, Herndon, VA), fetal bovine serum (FBS) (Gemini Bio-Products, Calabasas, CA), anti-actin, anti-RAR $\beta$, and anti-RAR $\alpha$ antibodies (Santa Cruz Biotechnology, Santa Cruz, CA). ECL Plus chemiluminescent immunoblotting detection reagents were obtained (GE Healthcare UK Limited, Buckinghamshire, UK) as was an anti-myc antibody (Covance, Berkeley, CA). The protease arrest protease inhibitor mixture was purchased (GenoTechnology, St. Louis, MO), as were SYBR Safe DNA stain, advanced RPM-1640, advanced DMEM, $\alpha$-MEM and LHC-8 media (Invitrogen, Carlsbad, CA).

Cell culture. NB4-S1 and NB4-R1, derived from parental NB4 cells, are clonal APL cell lines that are either sensitive or resistant to RA, respectively (21). Parental NB4 cells were derived from a patient with APL; these leukemic cells contain the $t(15 ; 17)$ chromosomal translocation that encodes the $\mathrm{PML} / \mathrm{RAR} \alpha$ fusion protein (22). Cell lines were cultured in their respective media containing penicillin $(100 \mathrm{U} / \mathrm{ml})$ and streptomycin $(100 \mu \mathrm{g} / \mathrm{ml})$ in $5 \% \mathrm{CO}_{2}$ and in a humidified incubator at $37^{\circ} \mathrm{C}$. NB4-S1 and NB4-R1 cells were cultured in advanced RPM-1640 medium supplemented with $2 \%$ FBS and $4 \mathrm{mM}$ L-glutamine. Chinese hamster ovary $(\mathrm{CHO})$ cells were cultured in $\alpha$-MEM medium supplemented with 5\% FBS and 2 mM L-glutamine. The green monkey kidney COS- 1 cell line was cultured in advanced DMEM medium supplemented with $2 \%$ FBS and $4 \mathrm{mM}$ L-glutamine. The immortalized human bronchial epithelial cell line BEAS-2B was cultured in LHC-9 serum-free medium, as previously described (12).

GOS2 RT-PCR assays. Total cellular RNA was isolated from NB4-S1 cells cultured at $2 \times 10^{5}$ cells $/ \mathrm{ml}$ in the presence of
RA $(1 \mu \mathrm{M})$ for $0,3,6,12,24$, and $48 \mathrm{~h}$ using TRI-reagent according to the manufacturer's protocol (Molecular Research Center, Inc., Cincinnati, OH). CHX (10 $\mu \mathrm{g} / \mathrm{ml})$ was added 30 min before RA-treatment. Complementary DNAs (cDNAs) were synthesized using SuperScriptII RNase $\mathrm{H}^{-}$reverse transcriptase (RT) according to the manufacturer's recommended procedures (Invitrogen). G0S2 mRNA was amplified from cDNA with the forward primer 5'-GGGAAGATGGTGAAG CTGTA-3' and reverse primer 5'-CTGGTCTCCCACAGTT CCTA-3' using Taq DNA polymerase (Invitrogen). Optimized polymerase chain reaction (PCR) assay conditions were used to amplify G0S2 cDNA and the 269 base pair (bp) PCR product was resolved on a $1 \%$ agarose gel with SYBR Safe DNA staining. As a control, human $ß$-actin mRNA was amplified from the same cDNA using the forward primer 5'GCGGGAAATCGTGCGTGACA-3' and reverse primer 5'AAGGAAGGCTGGAAGAGTGC-3' to produce a PCR fragment of $183 \mathrm{bp}$. G0S2 mRNA stability was investigated by treating $5 \times 10^{5} \mathrm{NB} 4-\mathrm{S} 1$ cells/ml with RA $(1 \mu \mathrm{M})$ for $15.5 \mathrm{~h}$ before addition of $2 \mu \mathrm{g}$ actinomycin $\mathrm{D} / \mathrm{ml}$. Total RNA was independently harvested at $0,1,2,4,6$ and $8 \mathrm{~h}$ after actinomycin D treatment. Stability of heteronuclear G0S2 RNA was investigated using RT-PCR assays and the forward primer 5'-CTATGAGCCCTCCCCAAGAT-3' and reverse primer 5'-TGCACACAGTCTCCATCAGG-3', generating a 264-bp product.

Full-length G0S2 mRNA was isolated from NB4-S1 cells, reverse transcribed and amplified using the forward primer 5'-AGATGGAAACGGTCCA-3' and reverse primer 5'-CTGGTCTCCCACAGTTCCTA-3', and cloned into the pCMV-Myc vector. This 330-bp PCR product was cloned into the pCRII-TOPO vector (Invitrogen) and subsequently cleaved with EcoRI restriction endonuclease. The EcoRI restricted fragment was then cloned in the sense orientation into the EcoRI site of the pCMV-Myc vector (Clonetech, Mountain View, CA). Restriction endonuclease digestions and sequence analyses were performed to confirm cloning of the desired species.

GOS2 reporter assays. The $2563-\mathrm{bp}$ G0S2 promoter sequence was amplified with a Pfx DNA polymerase (Invitrogen) from genomic DNA isolated from NB4-S1 cells, using the forward primer 5'-CTAGGAGCCAGGTTCTCTTTT-3' and reverse primer 5'-GGGCTTCAGCCACCAAAGAA-3'. This amplified product was cloned into the TOPO TA cloning vector (Invitrogen), which was excised with $K p n I$ and $X h o I$ restriction endonucleases and then cloned into the KpnI and XhoI sites of the pGL3-basic luciferase reporter plasmid (Promega, Madison, WI). The pGL3-G0S2-luciferase activity was measured using transient co-transfection assays. Briefly, each 6-well plate was seeded with $3 \times 10^{5} \mathrm{CHO}$ cells/well overnight before transfection. The G0S2 reporter construct $(0.25 \mu \mathrm{g} / \mu \mathrm{l})$, RAR expression vectors $(0.15 \mu \mathrm{g} / \mu \mathrm{l})$ and $\beta$-galactosidase expression vector $(0.25 \mu \mathrm{g} / \mu \mathrm{l})$ were respectively transfected into $\mathrm{CHO}$ cells using Effectene transfection reagent (Qiagen, Valencia, CA) as per the manufacturer's instructions. Following overnight transfection, cells were washed once with phosphate buffered saline (PBS) and fresh culture medium was added supplemented with RA $(10 \mu \mathrm{M})$ or vehicle (DMSO). Transfectants were cultured for $24 \mathrm{~h}$ before harvesting for luciferase 
and $\beta$-galactosidase activity assays. ß-galactosidase activity, however, was not used to normalize for luciferase activity as RA-treatment of transfectants was observed to suppress ßgalactosidase activity.

Identification of RAREs. RAREs in the G0S2 promoter were identified by a unidirectional nested deletion of the G0S2 promoter sequence cloned into the pGL3-G0S2-luciferase plasmid. The unidirectional nested deletion of the G0S2 promoter was performed, as previously described (23). Briefly, the pGL3-G0S2-luciferase vector was digested with KpnI and SpeI restriction endonucleases and an exonuclease III was then used to restrict the 3'-overhanging $S p I$ site. A series of truncated G0S2 promoter reporter vectors was generated by terminating exonuclease III activity at various times before re-ligation to the reporter plasmid. These serially-deleted G0S2 promoter constructs were examined for luciferase activities via transient co-transfection assays with RAR $\alpha$ in CHO cells without and with RA $(1 \mu \mathrm{M})$, as described above.

G0S2 RARE mutations. Putative G0S2 RARE half-sites were mutated to a non-functional RARE consensus sequence using two-step PCR assays (24) with the upstream primer 5'-AGTG CAGGTGCCAGAACATTT-3' and downstream reverse primer 5'-CATGTGATGTGTGCCCTGATAT-3'. These mutations were respectively generated with these primer pairs: 5'-GTCTACCAGAAACCTCCGTC-3' and 5'-GACGGAGG TTTCTGGTAGAC-3' (transversing wild-type TG $\rightarrow$ AA); 5'AACCTGGAGCGCAAAGTCAA-3' and 5'-TTGACTTT GCGCTCCAGGTT-3' (transversing wild-type GT $\rightarrow$ CG), and the upstream primer and 5'-TCCCTAGGTAGGAAGGCT GTA-3' (transversing wild-type $\mathrm{TG} \rightarrow \mathrm{GA}$ ), as displayed in Fig. 2B. The final PCR products contained KpnI and AvrII restriction sites, which were used to substitute the mutant PCR fragments into the same restriction sites in the wild-type G0S2 reporter construct. These mutants were DNA sequence confirmed. Promoter activities of these mutated RARE halfsites without (vehicle) and with RA $(1 \mu \mathrm{M})$ were measured as above.

G0S2 polyclonal antibody. Full-length G0S2 cDNA was cloned into the pQE30 vector (Qiagen) to express His-tagged G0S2 recombinant protein. Expression and purification of the His-tagged G0S2 protein were performed using Ni resin, as described (25). Polyclonal antisera were generated against G0S2 in the New Zealand White rabbit (Covance Research Products Inc., Denver, PA) using recombinant full-length human G0S2 protein.

GOS2 immunoblot analyses. Dose-dependent induction of G0S2 protein was studied using $5 \times 10^{5} \mathrm{NB} 4-\mathrm{S} 1$ cells/ml treated without RA or with $10^{1}, 10^{2}$, and $10^{3} \mathrm{nM}$ RA dosages. Cells were harvested and lysed with radio-immunoprecipitation assay (RIPA) buffer (20 mM HEPES at pH 7.4, 1\% Triton $\mathrm{X}-100,150 \mathrm{mM} \mathrm{NaCl}, 1 \mathrm{mM}$ EDTA, 1 mM EGTA, and 1X Protease Arrest). Total protein concentrations were determined with the Bio-Rad protein assay (Bio-Rad Laboratories, Inc., Hercules, CA) and SDS-PAGE and immunoblot analyses performed for detection of G0S2 and actin protein, respectively. RA induction of G0S2 protein was studied by culturing $1 \times 10^{6} \mathrm{NB} 4-\mathrm{S} 1$ cells with vehicle (DMSO), RA (10 nM) combined with or without the RAR pan-antagonist (10 nM or $100 \mathrm{nM}, \mathrm{LGD} 100815)$ and the RXR agonist (100 nM, bexarotene) for $24 \mathrm{~h}$ before total protein isolation with RIPA buffer. Total protein was subjected to SDS-PAGE and immunoblot analysis for G0S2 and actin proteins, respectively. G0S2 protein half-life in NB4-S1 cells $\left(5 \times 10^{5}\right.$ cells $\left./ \mathrm{ml}\right)$ was studied by induction with RA $(1 \mu \mathrm{M})$ overnight followed by addition of CHX (100 $\mu \mathrm{g} / \mathrm{ml}$ final concentration). NB4-S1 cells were harvested thereafter at $0,15,30,45$ and 60 min for total protein isolation with RIPA buffer. Immunoblot analysis was performed to detect G0S2 expression.

RA induction of murine GOS2 protein. A previously described transgenic APL mouse model (26) was examined. In vivo mouse APL model experiments were performed according to a protocol reviewed and approved by the Institutional Animal Care and Use Committee (IACUC) of Dartmouth College. Briefly, four female FVB mice (seven-weeks-old) were tail vein injected with $2 \times 10^{5}$ APL donor cells. An RA pellet (10 mg, Innovative Research of America, Sarasota, FL) was implanted under the skin in two recipient mice on day 20, after receiving APL donor cell injections. Prior dosage titration of donor cells indicated recipient mice developed APL by day 20 after this injection. APL mice were sacrificed using IACUC approved procedures $24 \mathrm{~h}$ after RA-treatment. Spleens were removed and washed with cold PBS and these tissues were dispersed in cold PBS supplemented with 1X Protease Arrest protease inhibitor mixture and $5 \mathrm{mM}$ EDTA and then filtered through a $40-\mu \mathrm{m}$ nylon mesh to harvest cells from splenic tissues. The harvested cells were resuspended in $20 \mathrm{ml} /$ spleen, cold reticulocyte suspension buffer $(10 \mathrm{mM}$ Tris- $\mathrm{HCl}$ $\mathrm{pH} 7.5,10 \mathrm{mM} \mathrm{NaCl}$, and $3 \mathrm{mM} \mathrm{MgCl}_{2}$ ) for $15 \mathrm{~min}$ on ice to lyse and thereby remove red blood cells. Cell suspensions were centrifuged, cell pellets were aliquoted and stored at $-80^{\circ} \mathrm{C}$. Total protein was isolated by resuspension of cell pellets in digitonin buffer (digitonin at $200 \mu \mathrm{g} / \mathrm{ml}, 250 \mathrm{mM}$ sucrose, $20 \mathrm{mM}$ HEPES, $10 \mathrm{mM} \mathrm{KCl}, 1.5 \mathrm{mM} \mathrm{MgCl}_{2}, 5 \mathrm{mM}$ EDTA and $1 \mathrm{X}$ Protease arrest protease inhibitor mixture, at $\mathrm{pH}$ 7.5) for $30 \mathrm{~min}$ on ice. Immunoblot analyses were performed to detect G0S2 and actin proteins.

GOS2 expression in de novo APL cells. Fresh APL cells were collected under Institutional Review Board protocol approval and with informed consent, and, as previously described (27), density-gradient separated cells with $85 \%$ blasts were placed in short-term tissue culture in the presence of RA $(1 \mu \mathrm{M})$ or vehicle (ethanol 1:1000). RNA was harvested after $24 \mathrm{~h}$, and the differentiation response was assessed by the percentage of nitrotetrazolium blue (NBT) stained cells after 5 days. After cDNA synthesis, RT-PCR assays for G0S2 were performed using a primer set that generates a 269-bp PCR product. The quality of the RNAs and cDNA products was assessed by a competitive RT-PCR assay for GAPDH in which a known quantity of a mimic competitor was added to each assay (27).

\section{Results}

$R A$ induction of GOS2 $m R N A$. Prior microarray analyses revealed G0S2 mRNA expression was increased following 
A

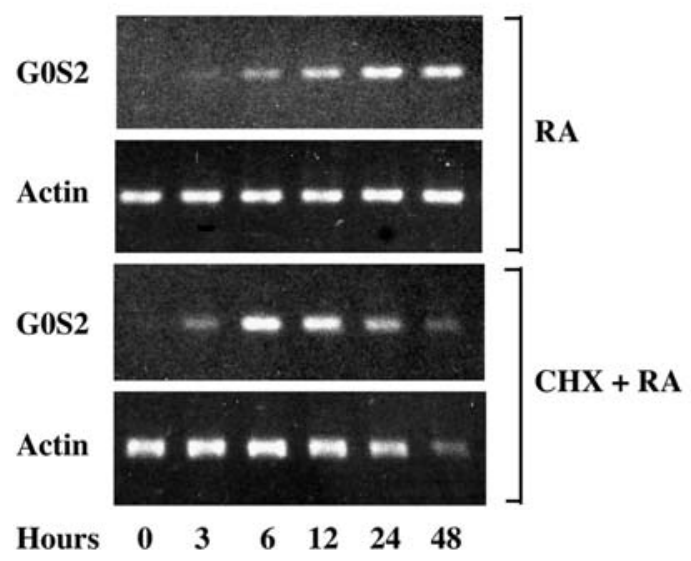

B

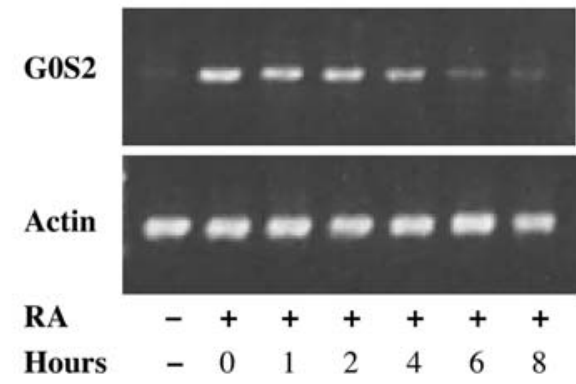

D
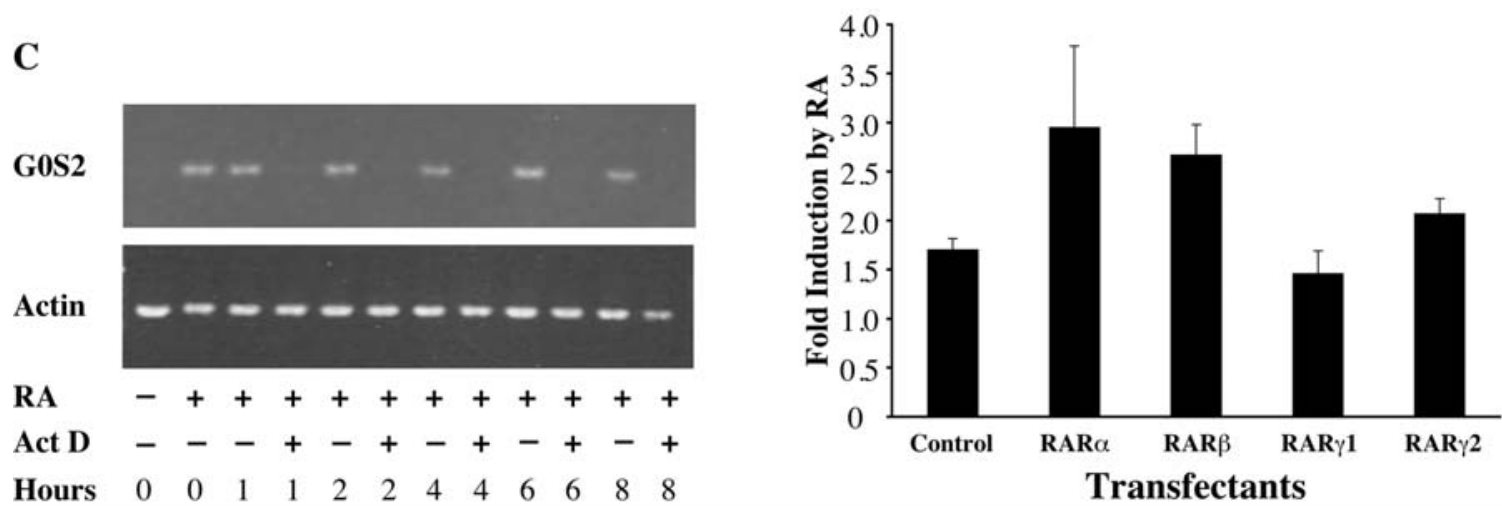

Figure 1. All-trans-retinoic acid (RA) induction of G0S2 mRNA and promoter activity. (A) NB4-S1 acute promyelocytic leukemia (APL) cells were cultured with RA $(1 \mu \mathrm{M})$ and/or co-treatment with cycloheximide (CHX, $10 \mu \mathrm{g} / \mathrm{ml})$ at the indicated times prior to total RNA isolation. Total RNA was then reverse transcribed and G0S2 and actin mRNAs were each amplified by PCR assays. Similar results were obtained from two independent experiments. (B) G0S2 mRNA stability determination. NB4-S1 cells were pretreated with RA $(1 \mu \mathrm{M})$ for $15.5 \mathrm{~h}$ prior to incubation with actinomycin D (Act D, $2 \mu \mathrm{g} / \mathrm{ml})$ at the indicated times. Total RNA was isolated, reverse transcribed and GOS2 and actin mRNAs each were amplified by PCR assays. Similar results were obtained from two independent experiments. (C) GOS2 heteronuclear RNA stability. Total RNAs in (B) were subjected to PCR assay using a primer set designed to amplify G0S2 heteronuclear RNA. (D) G0S2 promoter activity was measured using a luciferase reporter assay with and without exogenous RARs via transient transfection. The G0S2 reporter construct $(0.25 \mu \mathrm{g} / \mu \mathrm{l})$, indicated RARs $(0.15 \mu \mathrm{g} / \mu \mathrm{l})$ and $\beta$-galactosidase expression vectors were co-transfected overnight into CHO cells. DMSO (vehicle) and RA $(10 \mu \mathrm{M})$ were independently incubated with transfectants for $24 \mathrm{~h}$ before harvesting for reporter assays. The fold induction of G0S2 promoter activity increased over control by RA-treatment relative to vehicle-treated transfectants. Results were obtained from three independent experiments with error bars representing standard deviations.

RA-treatment of RA-sensitive NB4-S1 APL cells (14). The kinetics of RA mediated induction of G0S2 mRNA was determined in NB4-S1 cells using a semi-quantitative RT-PCR assay. G0S2 mRNA was robustly induced by RA $(1 \mu \mathrm{M})$ treatment at $3 \mathrm{~h}$ and continued to increase up to $48 \mathrm{~h}$ (Fig. 1A). This induction did not depend on de novo protein synthesis since pre-treatment of NB4-S1 with CHX did not prevent G0S2 induction by RA-treatment (Fig. 1A). In contrast, CHX augmented RA effects on G0S2 mRNA induction from 3 to $12 \mathrm{~h}$, as expected for a direct RA target gene (Fig. 1A). Treatment of NB4-S1 cells with actinomycin D (an inhibitor of RNA synthesis) revealed the G0S2 mRNA half-life was $\sim 5.5 \mathrm{~h}$ (Fig. 1B). RA induction of G0S2 heteronuclear RNA was also sensitive to the inhibitor of RNA synthesis since actinomycin D blocked the immature G0S2 RNA product after only $1 \mathrm{~h}$ of treatment (Fig. 1C).

Transcriptional activation of the GOS2 promoter by RAtreatment. To determine the mechanistic basis for G0S2
mRNA induction by RA-treatment, co-transfection of G0S2 reporter assays were performed, as described in Materials and methods. Fig. 1D displays G0S2 promoter activity in the presence of RA-treatment without and with exogenous RAR transfection. Over-expressed RAR $\alpha$ and RAR $\beta$ augmented the RA induction of G0S2 promoter activity by $\sim 3$-fold while RAR $\gamma 2$ augmented RA-mediated promoter activity by 2 -fold. $\mathrm{RA}$ also moderately induced G0S2 promoter activity in $\mathrm{CHO}$ cells without transfection of exogenous RARs and the level of induction was similar to that observed with RAR $\gamma 1$ transfection (Fig. 1D). Reporter assays were independently performed in BEAS-2B cells, with similar results obtained (data not shown).

The GOS2 promoter contains RAREs. The G0S2 promoter region that conferred RA induction was identified following unidirectional deletion of the G0S2 promoter. The studied sequences were located from -2324 to -1927 bp from the transcriptional start site +1 (Fig. 2A). Bioinformatic analysis 
A

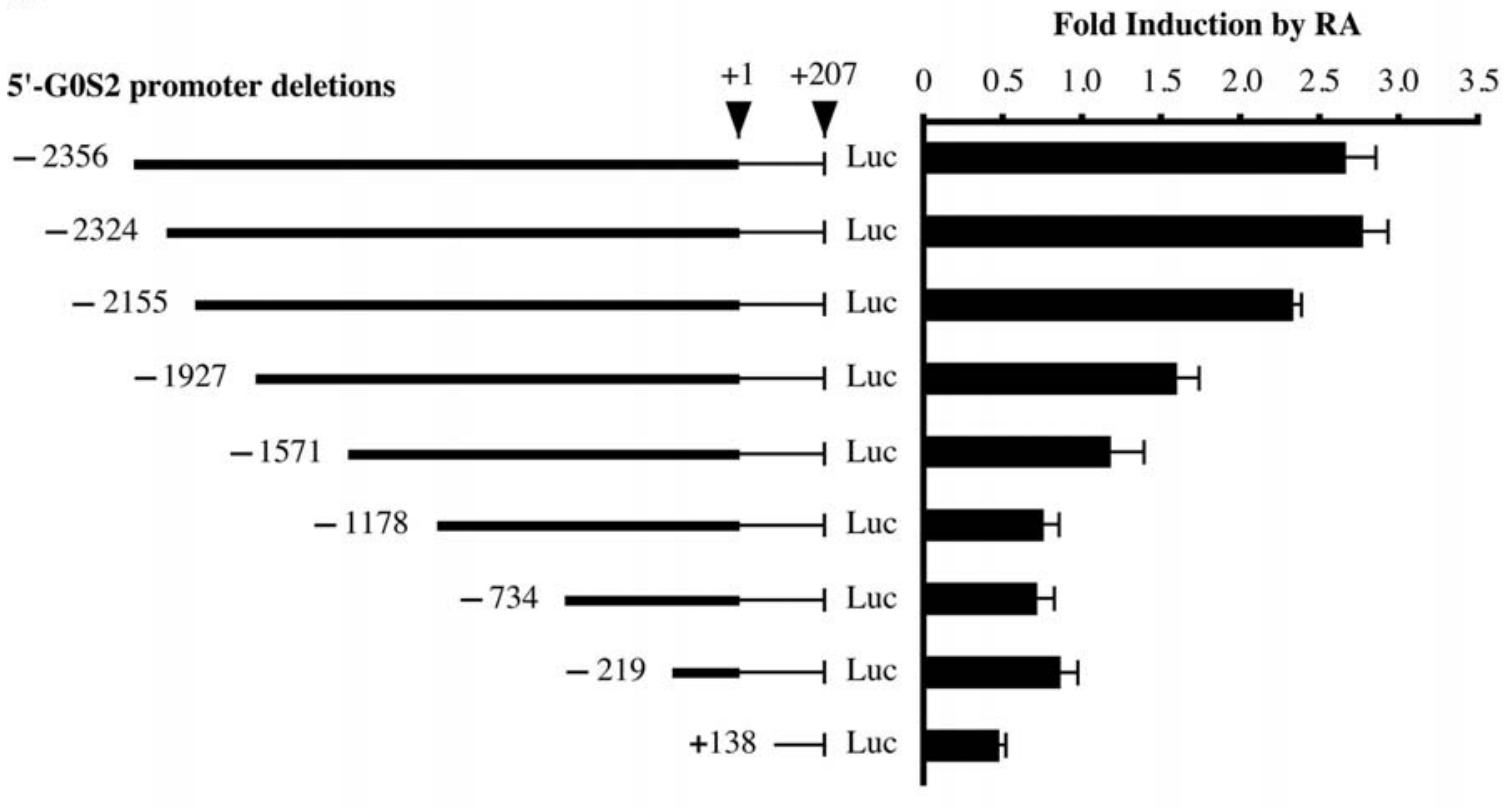

C

B

\section{5'-ctaccagTGACCTcegtccatggcacttgetgecectcetctgtcca AA} getcttaccaatatagctgetggaacetggAGGTCAaagtcaaattatca CG

aaaaaggaactgagetggtgatgtgcactaacacagcaaatcacaggaaa

ggggaacccaggtaaattacagcettcTGACCTagg-3'

GA

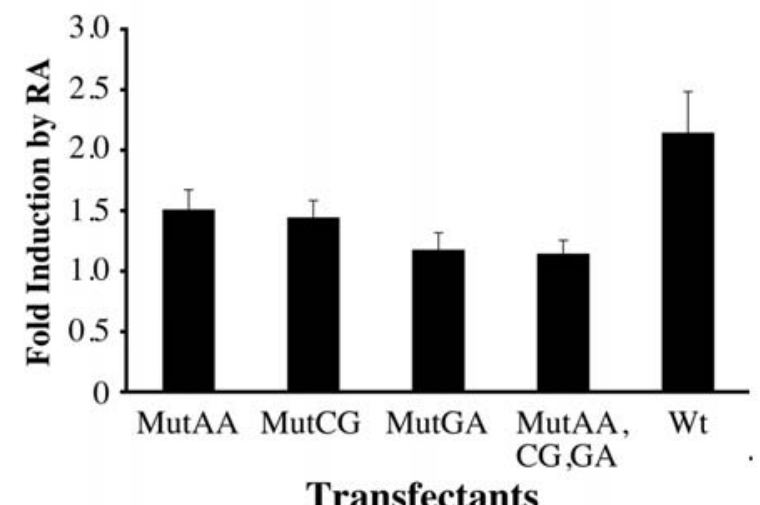

Figure 2. Unidirectional promoter deletions and RARE identification in the human G0S2 promoter. (A) The indicated G0S2 promoter elements were unidirectionally truncated at the indicated positions relative to the transcriptional start site (+1), where -2356 denotes the full-length wild-type G0S2 promoter cloned into the pGL3 luciferase vector. RA $(1 \mu \mathrm{M})$ induction of the G0S2 promoter luciferase activity for each transfectant was determined and reported as fold induction over control. Error bars represent standard deviation of six independent replicate experiments. (B) Bioinformatic analysis (28) predicted RAREs in the G0S2 promoter. The G0S2 promoter region was found to contain RARE half-sites (capitalized text). G0S2 promoter constructs containing mutated RARE half-sites were engineered. The mutated nucleotides are denoted, respectively, by two capitalized letters. (C) G0S2 reporter activity of each mutant G0S2 promoter (MutAA, MutCG, MutGA, MutAA,CG,GA) and wild-type (Wt) sequence was measured using luciferase reporter assays. The fold of RA $(1 \mu \mathrm{M})$-induced G0S2 promoter activity over control for each promoter construct was displayed with standard deviations depicted from three independent experiments.

(28) of the G0S2 promoter sequence revealed three RARE half-sites within this region (Fig. 2B). Mutation of each of these half-sites diminished RA activation of the G0S2 promoter, as shown in Fig. 2C.

RA-treatment induced GOS2 protein in NB4-S1 cells. Rabbit polyclonal antibody recognizing G0S2 protein was derived, as described in Materials and methods. This G0S2 antibody recognized a protein with the predicted G0S2 molecular weight of $11.3 \mathrm{kDa}$ in RA-treated NB4-S1 cells, but not in untreated cells and in COS-1 cells expressing transfected myc-tagged G0S2 (Fig. 3A). Specificity of the anti-G0S2 antibody was confirmed when this protein was probed with an anti-myc antibody, which recognized the myc-epitope of the transfected tagged-G0S2 protein (Fig. 3A). As expected, G0S2 mRNA induction by RA-treatment occurred in RAsensitive NB4-S1 cells and was accompanied by an increased of G0S2 protein in a time- and dose-dependent manner while G0S2 protein was undetected in RA-resistant NB4-R1 cells (Figs. 1A and $3 \mathrm{~B}$ and $\mathrm{C}$ ). Prominent G0S2 induction in NB4-S1 cells was observed after only $10 \mathrm{nM}$ of RA-treatment for $24 \mathrm{~h}$ (Fig. 3C). The half-life of G0S2 protein was $\sim 15 \mathrm{~min}$ (Fig. 3D). Induction of G0S2 protein in NB4-S1 cells by RA-treatment was inhibited with an RAR pan-antagonist, LGD100815 (Fig. 3E). The RXR agonist, bexarotene, did not induce G0S2 protein expression in NB4-S1 cells (Fig. 3E). 
A

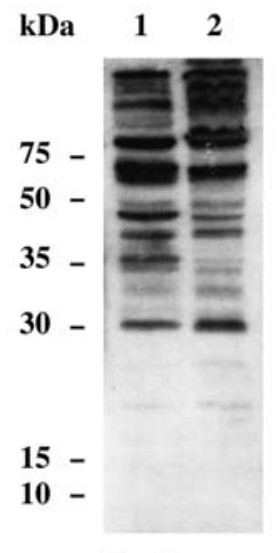

Pre-Immune Serum

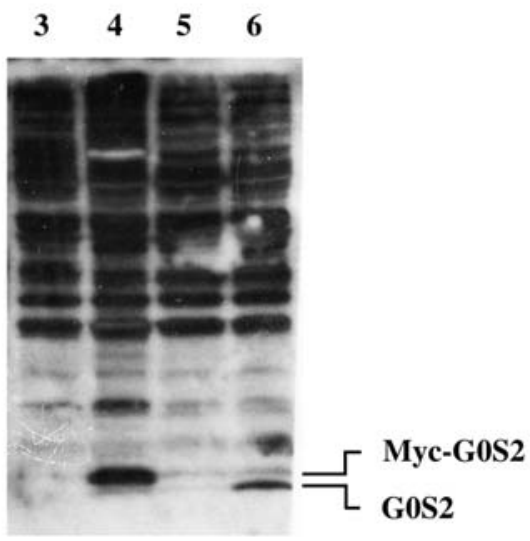

Anti-G0S2 Serum
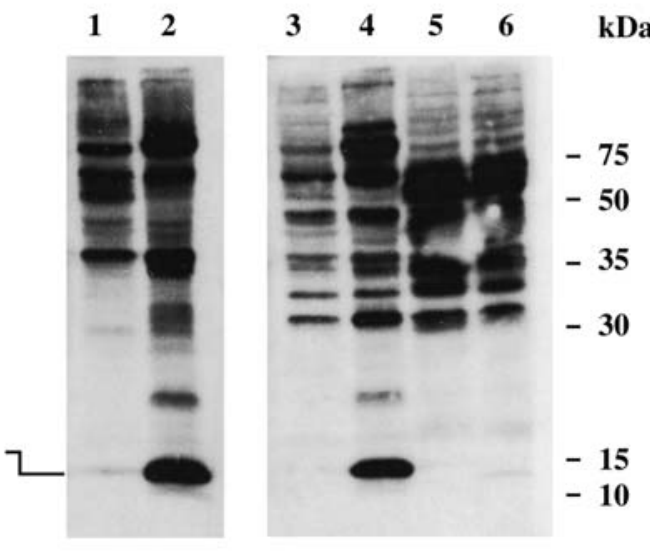

Anti-Myc Antibody
B

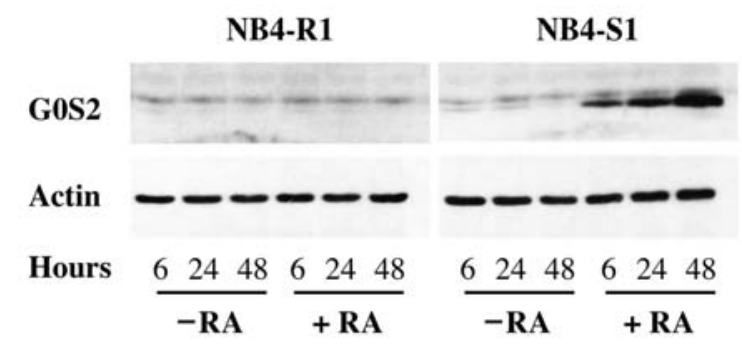

C

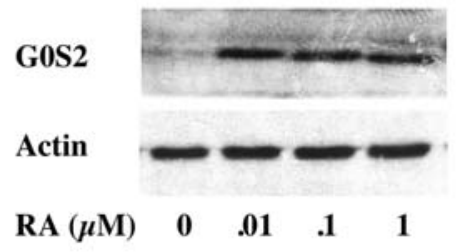

E

D

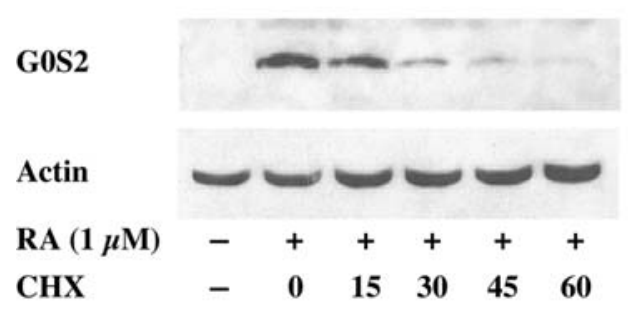

G0S2

Actin

RA (10 nM)

LGD100815 (10 nM)

LGD100815 (100 nM)

Bexarotene (100 nM)

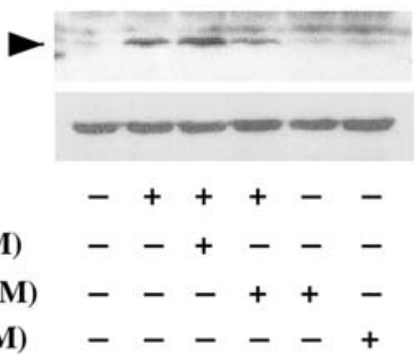

Figure 3. G0S2 protein induction by RA-treatment of NB4-S1 cells. (A) Rabbit polyclonal anti-G0S2 antibody was raised (see Materials and methods) and its specificity determined following SDS-PAGE and immunoblot analyses of COS-1 total cellular protein without (lane 1 and 3 ) and with (lanes 2 and 4 ) transfected myc-tagged G0S2 or RA-untreated (lane 5) or $24 \mathrm{~h}$ RA (1 $\mu \mathrm{M}$ )-treated (lane 6) NB4-S1 cells. The left panels displayed immunoblots probed with pre-immune rabbit serum and anti-G0S2 rabbit serum, respectively. The same immunoblots were stripped and re-probed with a monoclonal anti-Myc antibody (right panels). (B) RA induced G0S2 protein in RA-sensitive NB4-S1 cells, but not in RA-resistant NB4-R1 cells. NB4-S1 and NB4-R1 cells were untreated (-RA), or treated (+RA) with RA $(1 \mu \mathrm{M})$ for the indicated times. Total protein was isolated, quantified, resolved on SDS-PAGE, immunoblotted, and independently probed with anti-G0S2 and anti-actin antibodies, respectively. Resolved proteins were detected with chemiluminescent reagents and autoradiography. Experiments were performed twice with similar results obtained. (C) The RA dose-dependent G0S2 induction was studied after 24-h treatment of NB4-S1 cells with the indicated RA dosages. Total proteins were isolated, and immunoblotted for detection of G0S2 and actin proteins, respectively. Similar results were obtained from two independent experiments. (D) G0S2 protein stability was studied after RA-treatment of NB4-S1 cells with or without cycloheximide (CHX, $100 \mu \mathrm{g} / \mathrm{ml})$ treatment for the times indicated before isolation of total protein. G0S2 and actin proteins were detected, as above. Experiments were independently performed twice. (E) G0S2 protein was induced by RA-treatment. NB4-S1 cells were independently treated with RA, an RAR pan-antagonist (LGD100815), an RXR agonist (bexarotene) or RA + LGD100815 as indicated for $24 \mathrm{~h}$ before total protein isolation and immunoblot detection of G0S2 and actin proteins, respectively. Experiments were performed twice with similar results obtained.

Murine GOS2 protein induction by RA-treatment. To determine whether RA induced G0S2 in vivo, an established murine model of APL (26) was studied. As expected, RA-treatment significantly prolonged survival time of these APL mice [data not shown; 26]. Splenic enlargement was observed in the recipient mice 21 days after APL cell injection (data not 
B

A

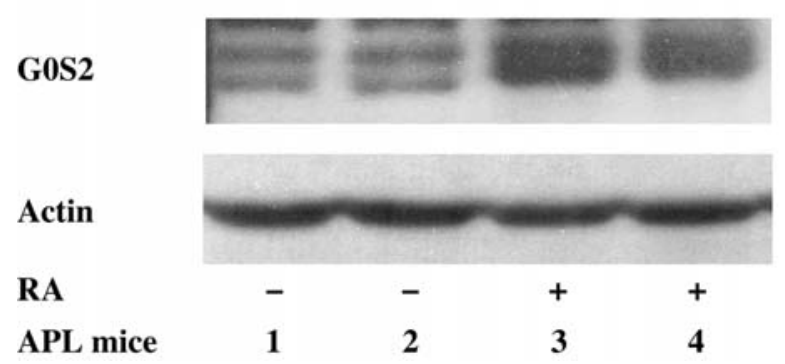

G0S2

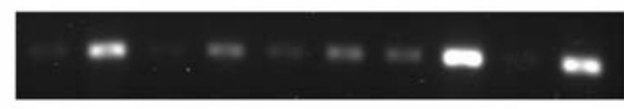

GAPDH

Mimic

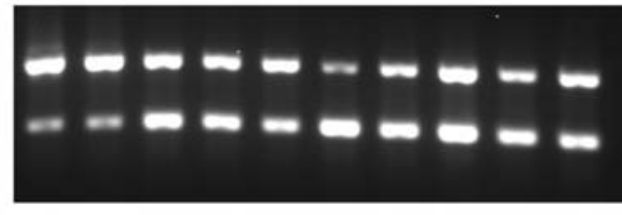

NBT (\%) - $\quad \begin{array}{lllllllll} & 2 & 86 & 2 & 67 & 5 & 98 & 4 & 98\end{array}$

RA

Cases

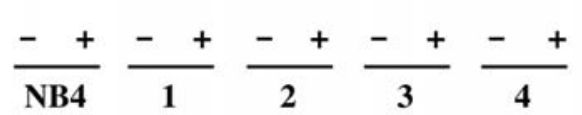

Figure 4. In vivo and ex vivo RA inductions of G0S2. (A) Female FVB recipient mice (seven-weeks-old) were tail vein injected with acute promyelocytic leukemia (APL) donor cells. RA pellets $(10 \mathrm{mg})$ were implanted into the indicated mice on day 20, after donor cell injection. Splenic tissues from these mice were harvested $24 \mathrm{~h}$ after RA-treatment and total proteins isolated. Immunoblots for G0S2 and actin proteins were performed and results displayed. (B) Ex vivo induction of G0S2 mRNA by RA-treatment. Total cellular RNA was independently isolated from APL primary cultures of four leukemic cases (cases 1-4) after RA $(1 \mu \mathrm{M})$-treatment for $24 \mathrm{~h}$ or with ethanol (1:1000) vehicle control, as described in Materials and methods. G0S2 cDNA was amplified using competitive RT-PCR assays for mimic-GAPDH as an amplification control. NB4-S1 (NB4) mRNA was used as a positive control for RA induction of G0S2 mRNA. The differentiation responses of the APL patient-derived cells to RA-treatment are depicted by the percentage of nitrotetrazolium blue (NBT) positive cells after RA-treatment and vehicle (ethanol) treatment, respectively.

shown). This splenic enlargement was indicative of APL development in these mice. Leukemia did not arise in control mice during the study period (data not shown). Total protein isolated from these spleens was subjected to immunoblot analyses, as described in Materials and methods. The polyclonal anti-G0S2 antibody recognized murine G0S2 that appeared at similar molecular weight as human G0S2 (Fig. 4A and data not shown). APL cells from these mice treated with RA showed a substantial increase of G0S2 protein as compared to control mice, as displayed in Fig. 4A.

GOS2 mRNA induction by RA-treatment of cultured human APL cells. RA is an established differentiation therapy for APL $(1,2)$. Whether RA induced G0S2 mRNA expression in cultures of APL cells isolated directly from patients was tested. APL cells from four cases exhibited elevated levels of G0S2 mRNA expression relative to vehicle controls when treated with RA $(1 \mu \mathrm{M})$ for $24 \mathrm{~h}$ (Fig. 4B). The extent of G0S2 mRNA induction after RA-treatment varied between cases (Fig. 4B). Notably, RA-treatment induced a differentiation response, as demonstrated by prominent presence of NBT positive cells following RA-treatment (Fig. 4B).

\section{Discussion}

G0S2 is a small, basic protein (11.3 kDa) with unknown functions that has potential sites for phosphorylation by protein kinase $\mathrm{C}$ and casein kinase II (18). Its promoter region has potential binding sites for the transcription factors AP1, AP2, AP3, and NFAT $(18,19)$. In vivo and in vitro G0S2 mRNA induction by a PPAR agonist and the presence of a PPAR response element within the G0S2 promoter are each consistent with G0S2 functioning as a PPAR target gene (17). Microarray analyses of APL (14), RT-PCR assays of G0S2 from NB4-S1 cells treated with RA (Fig. 1A), studies of wild-type and mutant G0S2 promoter activity in response to RA-treatment (Figs. 1D and 2A and C) and bioinformatic analysis of the
G0S2 promoter sequence (Fig. 2B) all indicate the G0S2 gene product is RA regulated in APL cells. RA induction of G0S2 mRNA progressively decreased after treatment with the RNA synthesis inhibitor actinomycin D (Fig. 1B). This indicated that RA induction of G0S2 was not due to RA stabilization of its mRNA. Induction of G0S2 mRNA by RA was tightly regulated with a half-life of $5.5 \mathrm{~h}$ (Fig. 1B). In contrast, G0S2 heteronuclear RNA was undetected after $1 \mathrm{~h}$ of treatment with this inhibitor of RNA synthesis, indicative of a rapid rate of post-transcriptional processing of heteronuclear G0S2 RNA to its mature mRNA (Fig. 2C).

RA induction of G0S2 expression was confirmed at the protein level. G0S2 protein expression increased as a function of time and RA dosage in NB4-S1 cells (Fig. 3B and C). RA was unable to augment G0S2 protein expression in RA-resistant NB4-R1 cells (Fig. 3B), as expected for an RAtarget gene. This deregulation was caused by a mutation identified in the ligand binding domain of PML/RAR $\alpha$ in NB4-R1 cells (29), which blocked G0S2 induction by RA (Fig. 3B). In addition, treatment of NB4-S1 cells with the RAR pan-antagonist LGD100815, inhibited RA mediated induction of G0S2 protein in a dose-dependent manner and an RXR ligand did not augment G0S2 protein expression (Fig. 3E). This result indicated G0S2 induction was RARdependent. G0S2 expression was modulated both at transcriptional (Fig. 1B and C) and post-translational levels with a protein half-life of only 15 min (Fig. 3D).

There was a likelihood that the anti-G0S2 antisera recognizing the human protein would recognize murine G0S2 since human G0S2 protein (gene bank accession no. M69199) has 78\% amino acid homology with mouse G0S2 (gene bank accession no. NM_008059). Indeed, G0S2 protein was markedly elevated upon RA-treatment in murine splenic tissues of APL harboring mice (Fig. 4A). This result established $\mathrm{RA}$ induction of G0S2 protein in vivo in an APL murine model (Fig. 4A). The relevance of G0S2 induction by RAtreatment was extended to the clinical context. APL cells 
derived directly from four APL cases were shown to induce G0S2 mRNA following RA-treatment (Fig. 4B). This occurred along with retinoid induced differentiation of these APL cases (Fig. 4B). Taken together, these results are consistent with G0S2 acting as a direct RA target gene.

It has been proposed that G0S2 expression in germ-line cells and blood mononuclear cells implicates a possible housekeeping role for G0S2 (16). However, our findings in the NB4-S1 APL cell line of a rapid induction of G0S2 by RA-treatment as well as its relatively short life, suggest it participates in a regulatory role beyond that of a housekeeping gene. Experiments are now underway to uncover the precise function of G0S2 in APL cell growth and differentiation.

\section{Acknowledgements}

The authors thank Dr Scott Kogan of the Department of Biochemistry and Biophysics, UCSF for providing the murine APL donor cells and for his helpful consultation on use of this APL model. These studies were supported by the National Institutes of Health (NIH) and National Cancer Institute (NCI) grants RO1-CA087546 (E.D.), RO1-CA062275 (E.D.), RO1-CA111422 (E.D.), RO1-CA56771 (R.G.), a Samuel Waxman Foundation Cancer Research Award (E.D.) and NIH T32-CA00959 (S.B.). E.D. is an American Cancer Society Clinical Research Professor.

\section{References}

1. Warrell RP Jr, Frankel SR, Miller WH Jr, et al: Differentiation therapy of acute promyelocytic leukemia with tretinoin (alltrans-retinoic acid). N Engl J Med 324: 1385-1393, 1991.

2. Melnick A and Licht JD: Deconstructing a disease: RAR $\alpha$, its fusion partners, and their roles in the pathogenesis of acute promyelocytic leukemia. Blood 93: 3167-3215, 1999.

3. Sporn MB, Roberts AB and Goodman DS (eds.): The Retinoids. Vols. 1 and 2. Academic Press, New York, 1984.

4. Raffelsberger W, Dembele D, Neubauer MG, Gottardis MM and Gronemeyer $\mathrm{H}$ : Quality indicators increase the reliability of microarray data. Genomics 80: 385-394, 2002.

5. Lee KH, Chang MY, Ahn JI, et al: Differential gene expression in retinoic acid-induced differentiation of acute promyelocytic leukemia cells, NB4 and HL-60 cells. Biochem Biophys Res Commun 296: 1125-1133, 2002.

6. Yang L, Zhao H, Li SW, et al: Gene expression profiling during all-trans-retinoic acid-induced cell differentiation of acute promyelocytic leukemia. J Mol Diagn 5: 212-221, 2003.

7. Freemantle SJ, Spinella MJ and Dmitrovsky E: Retinoids in cancer therapy and chemoprevention: promise meets resistance. Oncogene 22: 7305-7315, 2003.

8. Mangelsdorf DJ and Evans RM: Retinoid receptors as transcription factors. In: Transcriptional Regulation. McKnight SL and Yamamoto KR (eds.) Cold Spring Harbor Laboratory Press, New York, NY, pp1137-1167, 1992.

9. Cottone E, Orso F, Biglia N, Sismondi P and De Bortoli M: Role of coactivators and corepressors in steroid and nuclear receptor signaling: potential markers of tumor growth and drug sensitivity. Int J Biol Markers 16: 151-166, 2001.

10. Hu X, Li Y and Lazar MA: Determinants of CoRNR-dependent repression complex assembly on nuclear hormone receptors. Mol Cell Biol 21: 1747-1758, 2001.
11. Zhu J, Gianni M, Kop E, et al: Retinoic acid induces proteasomedependent degradation of retinoic acid receptor $\alpha(\operatorname{RAR} \alpha)$ and oncogenic RAR $\alpha$ fusion protein. Proc Natl Acad Sci USA 96: $14807-14812,1999$

12. Kitareewan S, Pitha-Rowe I, Sekula D, et al: UBE1L is a retinoid target that triggers PML/RAR $\alpha$ degradation and apoptosis in acute promyelocytic leukemia. Proc Natl Acad Sci USA 99: 3806-3811, 2002 .

13. Nervi C, Ferrara FF, Fanelli M, et al: Caspases mediate retinoic acid-induced degradation of the acute promyelocytic leukemia PML/RAR $\alpha$ fusion protein. Blood 92: 2244-2251, 1998.

14. Tamayo P, Slonim D, Mesirov J, et al: Interpreting patterns of gene expression with self-organizing maps: methods and application to hematopoietic differentiation. Proc Natl Acad Sci USA 96: 2907-2912, 1999.

15. Forsdyke DR: cDNA cloning of mRNAs which increase rapidly in human lymphocytes cultured with concanavalin-A and cycloheximide. Biochem Biophys Res Commun 129: 619-625, 1985.

16. Siderovski DP, Blum S, Forsdyke RE and Forsdyke DR: A set of human putative lymphocyte G0/G1 switch genes includes genes homologous to rodent cytokine and zinc finger proteinencoding gene. DNA Cell Biol 9: 579-587, 1990.

17. Zandbergen F, Mandard S, Escher P, et al: The $G_{0} / G_{1}$ switch gene 2 is a novel PPAR target gene. Biochem J 392: 313-324, 2005.

18. Russell L and Forsdyke DR: A human putative lymphocyte $\mathrm{G}_{0} / \mathrm{G}_{1}$ switch gene containing a $\mathrm{CpG}$-rich island encodes a small basic protein with the potential to be phosphorylated. DNA Cell Biol 10: 581-591, 1991 .

19. Cristillo AD, Heximer SP, Russell L and Forsdyke DR; Cyclosporin A inhibits early mRNA expression of $G_{0} / G_{l}$ switch gene 2 $\left(G_{0} S_{2}\right)$ in cultured human blood mononuclear cells. DNA Cell Biol 16: 1449-1458, 1997.

20. Pitha-Rowe I, Petty WJ, Kitareewan S and Dmitrovsky E: Retinoid target genes in acute promyelocytic leukemia. Leukemia 17: 1723-1730, 2003.

21. Nason-Burchenal K, Maerz W, Albanell J, Allopenna J, Martin P, Moore MAS and Dmitrovsky E: Common defects of different retinoic acid resistant promyelocytic leukemia cells are persistent telomerase activity and nuclear body disorganization. Differentiation 61: 321-331, 1997

22. Lanotte M, Martin-Thouvenin V, Najman S, Balerini P, Valensi F and Berger R: NB4, a maturation inducible cell line with $t(15 ; 17)$ marker isolated from a human acute promyelocytic leukemia (M3). Blood 77: 1080-1086, 1991.

23. Henikoff S: Unidirectional digestion with exonuclease III in DNA sequence analysis. Meth Enzymol 155: 156-165, 1987.

24. Kato JY, Matsuoka M, Strom DK and Sherr CJ: Regulation of cyclin D-dependent kinase 4 (cdk4) by cdk4-activating kinase. Mol Cell Biol 14: 2713-2721, 1994.

25. The QIAexpressionist: A handbook for high-level expression and purification of 6xHis-tagged protein. 5th edition. Qiagen, Valencia, CA, 2001.

26. Lallemand-Breitenbach V, Guillemin MC, Janin, A, et al: Retinoic acid and arsenic synergize to eradicate leukemic cells in a mouse model of acute promyelocytic leukemia. J Exp Med 189: 1043-1052, 1999.

27. Zhou DC, Hallam SJ, Lee SJ, Klein RS, Wiernik PH, Tallman MS and Gallagher RE: Constitutive expression of cellular retinoic acid binding protein II and lack of correlation with sensitivity to all-trans-retinoic acid in acute promyelocytic leukemia cells. Cancer Res 58: 5770-5776, 1998.

28. Quandt K, Frech K, Karas H, Wingender E and Werner T: MatInd and MatInspector-New fast and versatile tools for detection of consensus matches in nucleotide sequence data. Nucleic Acid Res 23: 4878-4884, 1995.

29. Nason-Burchenal K, Allopenna J, Begue A, Stehelin D, Dmitrovsky E and Martin P: Targeting of PML/RARalpha is lethal to retinoic acid-resistant promyelocytic leukemia cells. Blood 92: 1758-1767, 1998. 